\title{
Optimization of a Self-Excited Pulsed Air-Water Jet Nozzle Based on the Response Surface Methodology
}

\author{
Yong Wang 1 - Xiaolin Wang ${ }^{1}$ - Zilong Zhang ${ }^{1}$ - Yu Li ${ }^{1}$ - Houlin Liu ${ }^{1}$ * - Xiang Zhang ${ }^{2}$ - Marko Hočevar ${ }^{3}$ \\ ${ }^{1}$ Jiangsu University, Research Center of Fluid Machinery Engineering and Technology, China \\ ${ }^{2}$ Xihua University, Key Laboratory of Fluid and Power Machinery, China \\ ${ }^{3}$ University of Ljubljana, Faculty of Mechanical Engineering, Slovenia
}

A self-excited pulsed air-water jet (SEPAWJ) offers many advantages over other jets and has a large number of practical and industrial applications. In order to take better advantage of the SEPAWJ, response surface methodology (RSM) models were established with the experimental impact force characteristics as the dependent variable and three key nozzle parameters as the independent variable. Single and coupling factor effects of these three parameters (oscillation chamber length, oscillation chamber height, and diameter of the downstream nozzle) on performance of nozzle are analysed, and the structural parameters of optimum performance are calculated using RSM models. The external flow field, impact force and cleaning performance of SEPAWJ before and after optimization are analysed and compared experimentally. It is found that the significance levels of established average impact force and impact force amplitude RSM models are lower than 0.05 , and their error ratios between calculation and experiment under the optimum construction are both less than $5 \%$, which confirms their considerable reliability. Meanwhile, the final large water mass of optimized SEPAWJ is formed much earlier, and is more intensive and more concentrated. Compared with the original SEPAWJ nozzle, the impact force and impact force amplitude of optimized SEPAWJ nozzle are increased by $52.00 \%$ and $38.26 \%$, respectively. In addition, the cleaned area ratio of nozzle before and after optimization is $76 \%$ and $100 \%$ at 50 seconds, respectively, with an increase of $22.4 \%$.

Keywords: multiphase flow, impact force, cleaning performance, optimization, pulsed jet

Highlights

- The collapse of air bubbles and water surface tension transform continuous air-water mixed jet to discrete water masses with different speeds.

- At the same mass flow rate and time duration, bigger water masses from a pulsed jet offer larger volume and less number water masses which improves impact force amplitude and lowers impact force frequency.

- Multiphase periodic flow in the oscillation chamber of the pulsed air-water jet nozzle consists of shear layer flow formation, air suction from holes, air-water vorticity ring formation, air bubble breakage, and air mixing with the main stream.

- A self-excited pulsed air-water jet nozzle is optimized on the basis of Response Surface Methodology.

- Models are established with the experimental impact force characteristics as the dependent variable and three geometric dimensions as the independent variable.

\section{INTRODUCTION}

The high energy enabled by breaking of a continuous jet into a series of pulses has been widely used. Guha et al. [1] experimentally, numerically and theoretically investigated the very high speed water jet $(80 \mathrm{~m} / \mathrm{s}$ to $200 \mathrm{~m} / \mathrm{s}$ ) cleaning process, and the pressure distribution on the cleaning surface was assessed. Li et al. [2] investigated the effects of nozzle inner surface roughness on the cavitation erosion characteristics of submerged cavitating jets through experiments to push the erosion capability to a maximum, Chahine et al. [3] studied the Helmholtz nozzle and concluded that when the jet pulse frequency is consistent with the cavity's natural frequency, resonance will occur and the jet intensity will be improved. Scholars have studied the mechanism of pulsed jets through theoretical and experimental methods. Its most significant characteristic is periodic ejected water mass rather than continuous flow. Labus and Savanick determined that the peak value of pulsed air-water jet dynamic pressure is several times that of the steady and continuous water jet under the same working conditions, which greatly improves the cleaning effect. Researchers created many mechanical methods for producing high-energy water pulses repeatedly, such as rotating, reciprocating, or wobbling mechanisms. Glenn [5] mentioned an impulsive water cannon that can produce high energy. Grinspan and Gnanamoorthy [6] studied the high efficiency pulsed water jet acting on rock targets. Although these devices could drive large scale oscillations of the water flow and improve the erosion effect, they required high levels of mechanical maintenance which limits durability in harsh industrial environments. The complexity-related short life-time of the mentioned mechanical devices have prevented the development of a high-pressure pulsed water jet systems. However, "self-resonating 
jet" can be generated by the instability of shear flow, which could produce pulsed jets. Dehkhoda and Hood [7] mentioned the Helmholtz oscillator, which can form self-excited pulsed water jets. The vortices generated by the disturbed shear layer are continuously formed, enhanced, and weakened. The energy of the oscillation disturbance will increase significantly when the frequency of the process equals the natural frequency of the oscillator.

Many researchers have studied the self-excited water pulsed jet in many aspects. Tang et al. [8] built an oscillation frequency model of jet on the basis of hydro-acoustics and fluid dynamics for better understanding the principle of increasing jet pressure amplitude. He found that the oscillation frequency increased while increasing pump pressure and decreased while increasing cavity length, while there was an optimum cavity-length corresponding to the pressure peak value of the SEPAWJ. Hu [9] discussed the correlation of time-frequency distribution between the cervix cavity pressure pulsation signal and the shock pressure pulse signal in self-excited pulsed jet nozzle. He focused on the time-frequency rule of the pressure pulse signal, especially the inherent characteristic of frequency component. In order to improve the performance of the self-resonating cavitating waterjet under ambient pressures, $\mathrm{Li}$ et al. [10] experimentally studied the effects of the nozzle inner surface roughness by impinging the jets on pure aluminium specimens at various standoff distances. In addition, Chen et al. [11] investigated and compared the spray atomization properties and droplet turbulence characteristics of a twin-fluid nozzle with and without a self-excited vibrating cavity though a phase doppler particle analyser. He found that the self-excited vibrating cavity profoundly influenced the droplet turbulence characteristics by affecting the variation of droplet oscillation. In the presence of a self-excited vibrating cavity, the spray cone angle and the droplet number concentration increased significantly. The results indicated the significant role of the self-excited vibrating cavity in promoting fluid atomization.

Furthermore, Hall and Ewing [12] estimated the instantaneous turbulent velocity field in a threedimensional wall jet from the fluctuating wall pressure though a spectral linear stochastic estimation technique and found that the passage of the large-scale structures caused large, coherent lateral sweeps of fluid across the entire span of the wall jet. Besides, Li et al. [13] analysed effects of area discontinuity at nozzle inlet of Helmholtz oscillator and experimentally investigated it with respect to the axial pressure oscillations. It was found that area discontinuity had a capacity of enhancing their peak, which largely depended on the inlet pressure and standoff distance. The enhancement decreased with increasing inlet pressure and only happened within small standoff distances. Oh and Cho [14] carried out experimental cutting tests with water pressure, traverse speed of nozzle, and abrasive feed rate, and the energy loss was expressed by the energy term. Thakur and Singh [15] summarized the research progress and integrated function of abrasive waterjet machining in terms of mechanism and machining performances by using mathematical modelling and optimization methods. Alsoufi et al. [16] studied the effect of abrasive waterjet machining parameters on the surface texture quality of Carrara marble, and determined that the abrasive waterjet cutting process offers better cut surface texture quality of Carrara marble when the parameter conditions are constant.

With the wider application of pulsed water jet in engineering, scholars found that the self-excited pulsed air-water jet performed better in some fields. Wang and Zhou [17] used out the air-water and pulsed jets to break rock by combination. They optimized the parameters of pulsed jet device structure and the results show that erosion effect had increased significantly.

$\mathrm{Hu}$ et al. [18] described a new way of generating pulsed air-water jet by entraining and mixing air into the cavity of a pulsed water jet nozzle based on the theory of hydro-acoustics and fluid dynamics. A theoretical model was built, which described the frequency characteristic of the pulsed air-water jet and aiming at gaining a better understanding of the nozzle for generating pulses. In addition, the experimental results on specimens impinged by the pulsed water jet and pulsed air-water jet showed that the erosion rate increased slightly with air addition within a certain range of cavity length.

It can be seen from the above that the self-excited pulsed air-water jet is a new type of efficient cleaning jet, which combines the advantages of different kinds of jets. The periodic high-intensity impact of selfexcited pulsed air-water jet can quickly remove stains and its impact distribution is much wider, which significantly improves the cleaning effect.

In addition, the RSM is a statistical method to determine the optimum parameters, to solve the multivariate problems by using reasonable experimental design method, to obtain data through experiments and by using multivariate quadratic regression equation to obtain the functional relationship between factors. RSM was first proposed by Box and Wilson [19]. It is widely used in the fitting 
field of physical experiments in medicine, chemical industry, food and mechanical engineering. Vyavahare et al. [20] studied the effects of dye concentration, time, $\mathrm{pH}$, and temperature on sorption of malachite green (MG) dye using response surface methodology (RSM). Tang et al. [21] used the central composite design (CCD) and response surface methodology to optimize the working parameters of the sprinkler, and established multiple regression models, so that the vertical rocker sprinkler can achieve the best hydraulic performance in operation. Siddhant and Jignasa [22] investigated the optimum deposition conditions for preparation of copper zinc tin sulphur compounds (CZTS) thin films using the spray pyrolysis method based on the response surface methodology. Qi et al. [23] adopted box Behnken's design combined with response surface methodology to investigate the effect of $\mathrm{pH}$ value, contact time, initial concentration, and other adsorption parameters on Th(IV) adsorption capacity. Khoshnamvand et al. [24] used response surface methodology to study the effects of Ciprofloxacin (CIP) concentration, $\mathrm{CuO}$ dosage and $\mathrm{pH}$ value on Chemical Oxygen Demand (COD) removal rate, and established a second-order model based on CIP concentration, $\mathrm{CuO}$ dosage and $\mathrm{pH}$ value. Öztürk and Kahraman [25] analysed and determined the best grinding parameters of glass by response surface method, and studied the relationship between grinding characteristics and surface roughness by Box Behnken design (BBD) to design the experiment. Gnanavelbabu and Saravanan [26] studied the abrasive water jet machining (AWJM) process for the machining of Grade 5 Titanium alloy through response surface methodology (RSM) and adopted BBD to optimize the abrasive water jet machining process.

Especially, in the aspect of the AWJ cutting, many scholars also use response surface method to study. Dani and Shah [27] used response surface methodology to study the effects of transverse velocity, water pressure, and tool spacing on the removal rate and surface roughness. Karakurt et al. [28] studied the effects of the abrasive waterjet operating variables on the kerf angle and the material properties were correlated with the kerf angle through response surface methodology. Gupta et al. [29] adopted the abrasive water jet cutting (AWJ) process to study experimental investigation parameters on kerf taper angles of makrana white marble through changing the water pressure, nozzle transverse speed and abrasive flow rate; analysis of variance (ANOVA) was used to determine the main statistically significant process factors affecting the kerf taper angle. Mohammad and Jabari [30] studied the cooling of photovoltaic modules through multi-nozzle jet impingement cooling (JIC) system. The effects of the number of nozzles, their sizes (diameter), and the dimensionless nozzle-to-photovoltaic (PV) spacing on the overall performance of the JIC system were studied using a response surface methodology.

Many experiments are needed to study the influence of various factors on the performance of self-excited pulsed air-water jet nozzle and their relationship. The response surface methodology can shorten the optimization process with less experimental time compared with traditional optimization methods. In the present paper, SEPAWJ was applied to toilet nozzle, and the second-order mathematical model of RSM was established for the SEPAWJ characteristics of impact force characteristics (average impact force $F$, impact force amplitude $\Delta F$ ) under different chamber and downstream nozzle parameters measured by experiments. The significance of the coefficients of the model and regression equation was tested. The influence of interaction items and single factors on the SEPAWJ impact characteristics was obtained. Structural parameters for optimum performance were calculated with RSM equations and the performance of the nozzle before and after optimization was compared experimentally. Comparison supplements the previous related research and provides useful information for better applications of SEPAWJ.

\section{OPERATING PRINCIPLES OF A SEPAWJ NOZZLE}

The SEPAWJ has a more pronounced cleaning effect than the continuous jet because of its periodic water mass delivery. The peak value of jet-forced pressure of the pulsed air-water jet is several times that of the continuous water jet under the same working conditions. Fig. 1 shows the operating principles of a nozzle producing SEPAWJ.

As shown in Fig. 1, the shear layer flow flows to the air holes on both sides of the chamber, which reduces the holes pressure to lower than atmospheric pressure. Air is sucked from the air holes and forms a series of discrete bubbles. The inclusion of bubbles to the fluids shear layer enables formation of air-water vorticity rings due to the confinement by the chamber wall. Some bubbles in air-water vorticity rings break up and produce pressure pulses. This results in small bubbles mixing into the main stream flow and causing pressure and velocity fluctuations. The air-mixed main stream flow passes through the downstream nozzle and eventually forms an air-water pulsed jet. As discussed, the series phenomena: "shear layer 


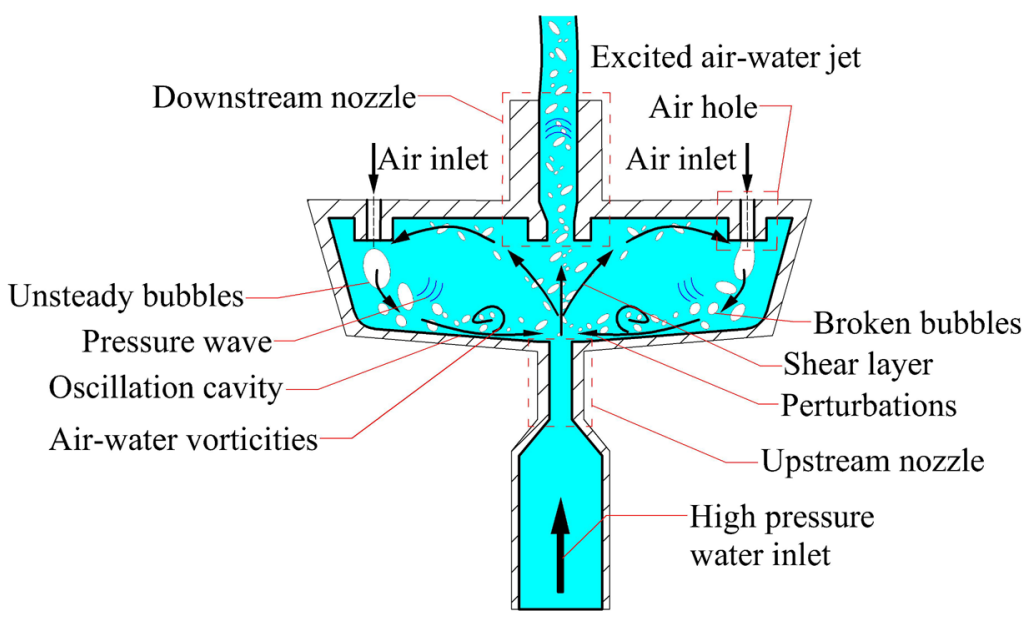

Fig. 1. Schematic diagram of a SEPAWJ nozzle and its operating principles

flow formation", "air suction from holes", "air-water vorticity rings formation", "air bubble breakage", and "air mixing with main stream" develop quasi-periodic operations of the pulsating air-water jet under certain working conditions.

a)

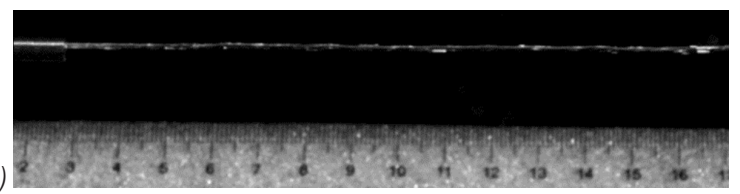

b)

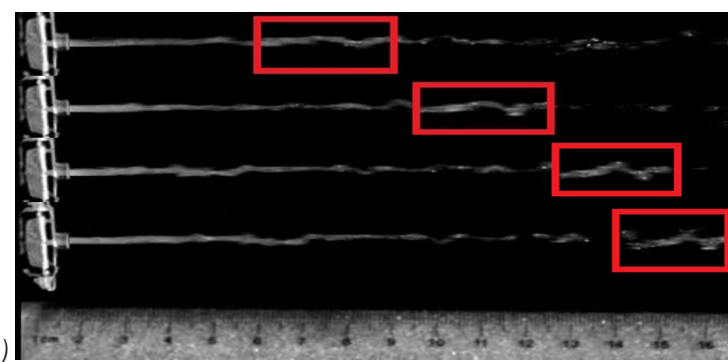

Fig. 2. Visualization of continuous jet and EPAWJ; a) continuous jet; b) EPAWJ

Fig. 2 shows visualization of the continuous jet and SEPAWJ. As shown in Fig. 2a, the continuous water jet is thin, straight, and stable for the entire observation length. Because of its stability, its cleaning area and the impact force amplitude are small. As shown in Fig. 2b, the air bubbles in the airwater jet collapse and the jet becomes unstable at 6 $\mathrm{cm}$. Because non-stationary and random phenomena, like the uneven distribution of air bubbles in the entire jet, unstable and turbulent flow within the jet, pressure instabilities within the water jet, surface tension and the random air bubble collapse, the continuous airwater jet breaks into small discrete water segments at around $10 \mathrm{~cm}$ distance from the downstream. All of this results in different speeds of individual segments. The faster segments catch up with the slower segments and eventually form a large water segment at around $15 \mathrm{~cm}$ from the downstream nozzle. Continuous occurrence of pulsed large water segments forms the SEPAWJ.

\section{EXPERIMENTAL SETUP AND PROCEDURES}

The design of the experimental SEPAWJ nozzle is shown in Fig. 3. The experimental SEPAWJ nozzle parameters before optimization are shown in Table 1. The nozzle is $3 \mathrm{D}$-printed with photosensitive resin as material, which is waterproof and not easy to deform. The performance parameters of material are shown in Table 2 .

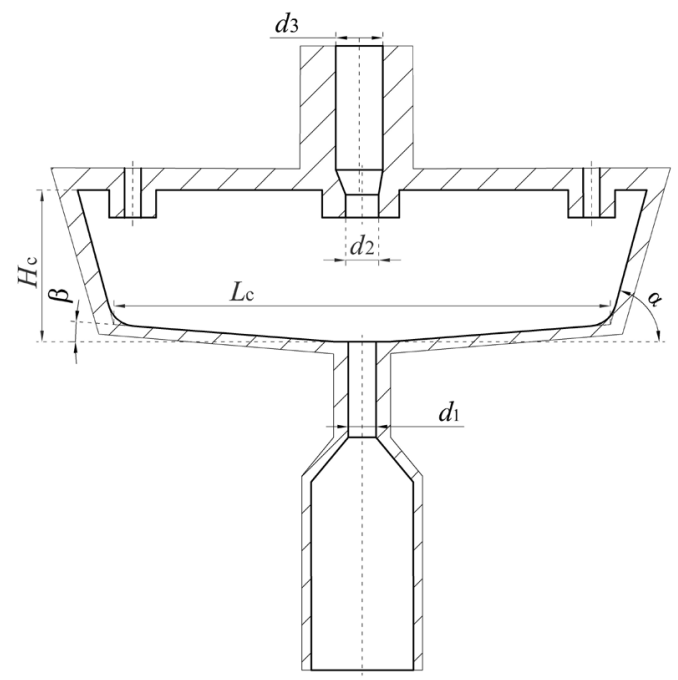

Fig. 3. Schematic diagram of the SEPAWJ nozzle 
Table 1. The main structural parameters of the SEPAWJ nozzle before optimization

\begin{tabular}{llc}
\hline Parameter & \multicolumn{1}{c}{ Name } & Size \\
\hline$d_{1}$ & Outlet diameter of upstream nozzle & $1 \mathrm{~mm}$ \\
\hline$d_{2}$ & Inlet diameter of downstream nozzle & $1.4 \mathrm{~mm}$ \\
\hline$d_{3}$ & Outlet diameter of downstream nozzle & $1.7 \mathrm{~mm}$ \\
\hline$H_{c}$ & Oscillation chamber height & $5.5 \mathrm{~mm}$ \\
\hline$L_{c}$ & Oscillation chamber length & $16 \mathrm{~mm}$ \\
\hline$\alpha$ & $\begin{array}{l}\text { Inclination angle of oscillation chamber side } \\
\text { wall }\end{array}$ & $60^{\circ}$ \\
\hline$\beta$ & $\begin{array}{l}\text { Inclination angle of oscillation chamber } \\
\text { bottom wall }\end{array}$ & $4^{\circ}$ \\
\hline
\end{tabular}

Table 2. The main performance parameters of the resin material

\begin{tabular}{lc}
\hline Heat distortion temperature & $47^{\circ} \mathrm{C}$ \\
\hline Hardness & 87 \\
\hline Tensile strength (fracture) & $56 \mathrm{MPa}$ \\
\hline Tensile modulus & $2800 \mathrm{MPa}$ \\
\hline Ductility (tensile) & $4 \%$ \\
\hline Impact strength & $25 \mathrm{~J} / \mathrm{m}$ \\
\hline Bending strength & $84 \mathrm{MPa}$ \\
\hline Bending modulus & $2490 \mathrm{MPa}$ \\
\hline Poisson's ratio & 0.41 \\
\hline
\end{tabular}

The experimental setup is arranged from several subsystems, indicated by different colours in Fig. 4; water supply and conditioning, nozzle, SEPAWJ cleaning evaluation, force measurement, flow visualization, and control systems.
As impact force is the most important evaluating indicator of a jet, its average impact force and impact force amplitude, as well as impact force frequency of fluctuations are essential to be measured and analysed for SEPAWJ performance evaluation under different working conditions and parameters. A miniature impact force sensor (model: LH-S09A) was used to measure the SEPAWJ impact force. It was mounted at a distance $150 \mathrm{~mm}$ away from the downstream nozzle outlet.

The size and shape of the discrete water segments formed within the discrete jet from the downstream nozzle outlet have a great influence on the cleaning performance. Therefore, flow field visualization was used to provide better understanding of the SEPAWJ characteristics LH-S09A performance under different nozzle structure parameters. A high-speed image acquisition system (camera model: MotionPro Y4) for capturing flow field was used for the SEPAWJ jet evaluation.

Experimental testing of the cleaning performance of the SEPAWJ is necessary and the steps to do so are as follows:

1. Evenly apply $10 \mathrm{~g}$ soybean paste as a dirt on a $100 \mathrm{~mm} \times 20 \mathrm{~mm}$ water-resistant sandpaper (model: P1500).

2. The direction of nozzle outlet is at 25 degrees angle relative to the paper surface placed horizontally. The distance between nozzle outlet and sandpaper is $15 \mathrm{~cm}$.

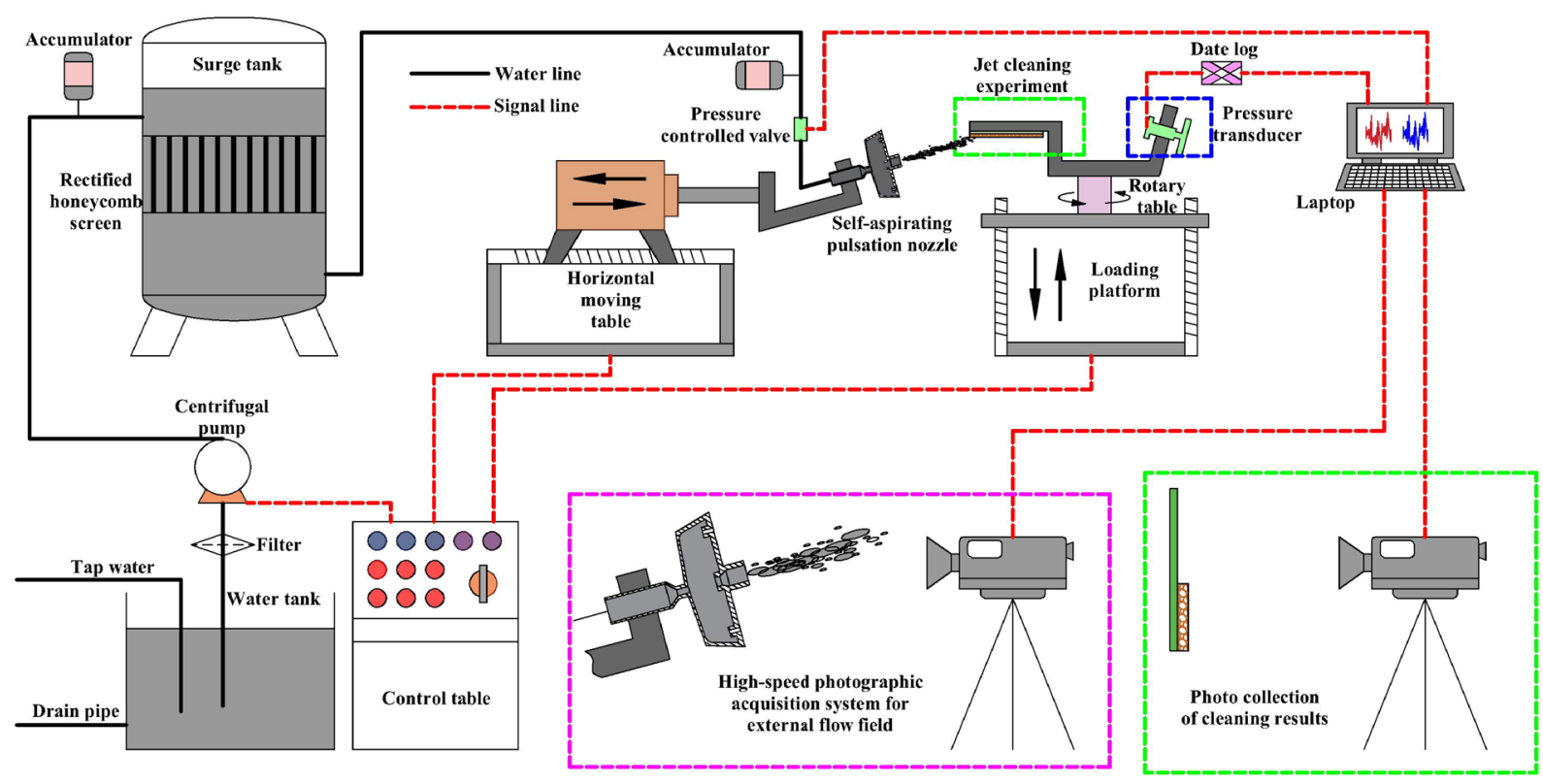

Fig. 4. Schematic diagram of the experimental setup 
3. The image of residual dirt is acquired every 10 seconds for measurement of cleaned area ratio.

4. The cleaned area ratio was calculated from acquired images by using image analysis software through image pre-processing, greying, image segmentation, calibration, and area calculation.

Fig. 5 shows residual dirt image before and after the grey level thresholding by image analysis software.

Furthermore, in order to reduce the influence of testing system pressure amplitude, a centrifugal pump is used as pumping device and a surge tank and two accumulators are installed. The pressure controlled valve in upstream of the nozzle ensures that the dynamic pressure of the nozzle inlet is stable at 0.12 $\mathrm{MPa}$.

a)
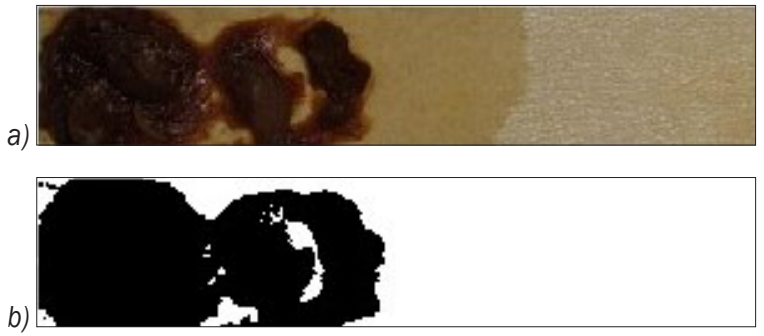

Fig. 5. Before and after the gray processing of residual dirt area by image analysis software; a) before the grey processing of residual dirt area; $b$ ) after the grey processing of residual dirt area

\section{RESULTS AND ANALYSIS}

\subsection{Design of Experiment and Measurement Results}

Tang et al. [8] compared self-excited oscillation pulsed jet and continuous jet for time domain impact characteristics under the same inlet pressure and mass flow rate. They found that the impact force amplitude of continuous jet is small and that of the self-excited oscillation pulsed jet is such significant, although the average impact force of self-excited oscillation pulsed jet is slightly smaller because of energy lost from gas bubbles breakings and associated turbulent losses. The average impact force and impact force amplitude are important parameters in evaluating a jet nozzle.

Based on our previous research, it was found that the oscillation chamber length, oscillation chamber height and diameter of the downstream nozzle each have a sensitive effect on the average impact force and impact force amplitude of the jet nozzle separately. However, single factor analysis has some disadvantages in the optimization; for example, it needs a lot of experiments and the coupling effect of three parameters are unknown.
The RSM enables seeing how changes to each input parameter affect a selected output parameter, showing the coupling relationship between variables and responses. The RSM, especially the BBD used in this research, is a technique in which orthogonal arrays are used to investigate design parameters.

Table 3. Initial design parameters and constraint values

\begin{tabular}{lccc}
\hline Quantity & $\begin{array}{c}\text { Lower value } \\
{[\mathrm{mm}]}\end{array}$ & $\begin{array}{c}\text { Base value } \\
{[\mathrm{mm}]}\end{array}$ & $\begin{array}{c}\text { Largest value } \\
{[\mathrm{mm}]}\end{array}$ \\
\hline $\begin{array}{l}\text { Inlet diameter of } \\
\text { upstream nozzle }\end{array}$ & 1.2 & 1.4 & 1.6 \\
\hline Chamber length & 12 & 16 & 18 \\
\hline Chamber height & 5.1 & 5.5 & 5.9 \\
\hline
\end{tabular}

As a result, in this paper, the average impact force $F$ and impact force amplitude $\Delta F$ were selected as target dependent variables to establish RSM model respectively and oscillation chamber length, oscillation chamber height and diameter of the downstream nozzle are taken as experimental variables. The initial design parameters and constraint values are shown in Table 3.

According to the initial design parameters and selected constraint values presented in Table 3, 17 test cases were obtained by Box-Behnken method in Software Design-Expert 10.0, and the average impact force $F$ and impact force amplitude $\Delta F$ for each test scheme were obtained experimentally, as shown in Table 4.

\subsection{Average Impact Force RSM Model}

An ANOVA, which a data mining technique, is carried out to differentiate the contributions to the variance of the response surface from the model. To evaluate the effect of each design variable, the total variance of the model is decomposed into that of each design variable and their interactions. This method is used to identify unnecessary terms in model function.

Table 5 shows the RSM summary of the RSM model and ANOVA for average impact force. For the established average impact force of the RSM model, the significance levels of inlet diameter of downstream nozzle $(A)$ and chamber length $(B)$ are less than 0.01 , which means that these two single factors have a very significant effect on average impact force $F$. Similarly, the significant level of the interaction term $(A B)$ is less than 0.05 , which indicates that it has a significant coupling effect on the average impact force $F$.

The significance level of a certain item is inversely proportional to the influence level of the item on the average strike force. Therefore, the order 
Table 4. Experimental variables and obtained results

\begin{tabular}{cccccc}
\hline No. & $\begin{array}{c}\text { Downstream nozzle inlet } \\
\text { diameter } A[\mathrm{~mm}]\end{array}$ & $\begin{array}{c}\text { Chamber length } \\
B[\mathrm{~mm}]\end{array}$ & $\begin{array}{c}\text { Chamber height } \\
C[\mathrm{~mm}]\end{array}$ & $\begin{array}{c}\text { Average impact force } \\
\text { Impact force amplitude }\end{array}$ & \begin{tabular}{c}
$\Delta F[\mathrm{~N}]$ \\
\hline 1
\end{tabular} \\
1.6 & 20 & 5.5 & 0.0942 & 0.0121 \\
\hline 2 & 1.4 & 16 & 5.5 & 0.1361 & 0.0163 \\
\hline 3 & 1.4 & 12 & 5.9 & 0.1145 & 0.0103 \\
\hline 4 & 1.2 & 16 & 5.1 & 0.1013 & 0.0148 \\
\hline 5 & 1.2 & 16 & 5.9 & 0.0948 & 0.0131 \\
\hline 6 & 1.6 & 12 & 5.5 & 0.0545 & 0.0088 \\
\hline 7 & 1.6 & 16 & 5.9 & 0.0923 & 0.0115 \\
\hline 8 & 1.4 & 12 & 5.1 & 0.1184 & 0.0113 \\
\hline 9 & 1.4 & 16 & 5.5 & 0.1361 & 0.0163 \\
\hline 10 & 1.4 & 16 & 5.5 & 0.1361 & 0.0163 \\
\hline 11 & 1.6 & 5.1 & 0.0939 & 0.0124 \\
\hline 12 & 1.4 & 5.1 & 0.1348 & 0.0159 \\
\hline 13 & 1.4 & 20 & 5.5 & 0.1361 & 0.0163 \\
\hline 14 & 1.2 & 16 & 5.5 & 0.1074 & 0.0143 \\
\hline 15 & 1.4 & 20 & 5.9 & 0.1194 & 0.0151 \\
\hline 16 & 1.4 & 20 & 5.5 & 0.1361 & 0.0163 \\
\hline 17 & 1.2 & 16 & 5.5 & 0.0895 & 0.0095 \\
\hline
\end{tabular}

of the influence of single factors the average impact force $F$ is: chamber length $(B)>$ inlet diameter of downstream nozzle $(A)>$ chamber height $(C)$. The order of the influence of interaction items on the average impact force $F$ is: downstream nozzle and chamber height $(A C)>$ chamber length and chamber height $(B C)>$ downstream nozzle and chamber length $(A B)$.

Table 5. Summary of RSM model and ANOVA for average impact force

\begin{tabular}{lcccc}
\hline Source & $\begin{array}{c}\text { Sum of } \\
\text { squares }\end{array}$ & $\begin{array}{c}\text { Degrees of } \\
\text { freedom }\end{array}$ & $\begin{array}{c}\text { Mean } \\
\text { square }\end{array}$ & $\begin{array}{c}\text { Significance } \\
\text { level }(P \text {-value })\end{array}$ \\
\hline Model & $8.225 \mathrm{E}-003$ & 9 & $9.139 \mathrm{E}-004$ & 0.0002 \\
\hline$A$ & $6.680 \mathrm{E}-004$ & 1 & $6.680 \mathrm{E}-004$ & 0.0039 \\
\hline$B$ & $6.827 \mathrm{E}-004$ & 1 & $6.827 \mathrm{E}-004$ & 0.0037 \\
\hline$B$ & $1.748 \mathrm{E}-004$ & 1 & $1.748 \mathrm{E}-004$ & 0.0472 \\
\hline$A B$ & $1.796 \mathrm{E}-004$ & 1 & $1.796 \mathrm{E}-004$ & 0.0444 \\
\hline$A C$ & $5.550 \mathrm{E}-005$ & 1 & $5.550 \mathrm{E}-005$ & 0.2622 \\
\hline$B C$ & $3.306 \mathrm{E}-005$ & 1 & $3.306 \mathrm{E}-005$ & 0.3779 \\
\hline Residual & $2.613 \mathrm{E}-004$ & 7 & $3.732 \mathrm{E}-005$ & \\
\hline Lack of fit & $2.613 \mathrm{E}-004$ & 3 & $8.708 \mathrm{E}-005$ & \\
\hline Pure error & 0.000 & 4 & 0.000 & \\
\hline Cor Total & $8.486 \mathrm{E}-003$ & 16 & & \\
\hline \multicolumn{5}{c}{003} \\
\hline
\end{tabular}

Fig. 6 shows the average impact force as a function of interaction items consisting of the downstream nozzle inlet diameter, chamber length, and chamber height. The interaction term $(A B)$ consisting of the length of downstream nozzle and chamber length has a very significant effect on the average impact force, while the other two interaction terms are less significant. Therefore, the parameters of downstream nozzle inlet diameter and chamber length are more critical for obtaining larger average impact force.

According to the response surface regression equation, when the downstream nozzle inlet diameter is $1.37 \mathrm{~mm}$, the chamber length is $18.12 \mathrm{~mm}$, and the chamber height is $4.80 \mathrm{~mm}$, the average impact force is expected to reach the maximum value of $0.1434 \mathrm{~N}$.

The RSM equation of average impact force $F$ is as follows:

$$
\begin{aligned}
F & =+0.14-0.009138 A+0.009238 B \\
& -0.004675 C+0.0067 A B+0.003725 A C \\
& -0.002875 B C-0.036 A^{2}-0.012 B^{2} \\
& -0.00195 C^{2} .
\end{aligned}
$$

It can be seen from Table 5 that the regression model $P=0.0002<0.01$ shows that the model has a very significant impact on the impact force $F$, and can well describe the relationship between the structural parameters and the impact force $F$.

\subsection{Average Impact Force Amplitude of the RSM Model}

The response surface regression equation of impact force amplitude $\Delta F$ is as follows: 

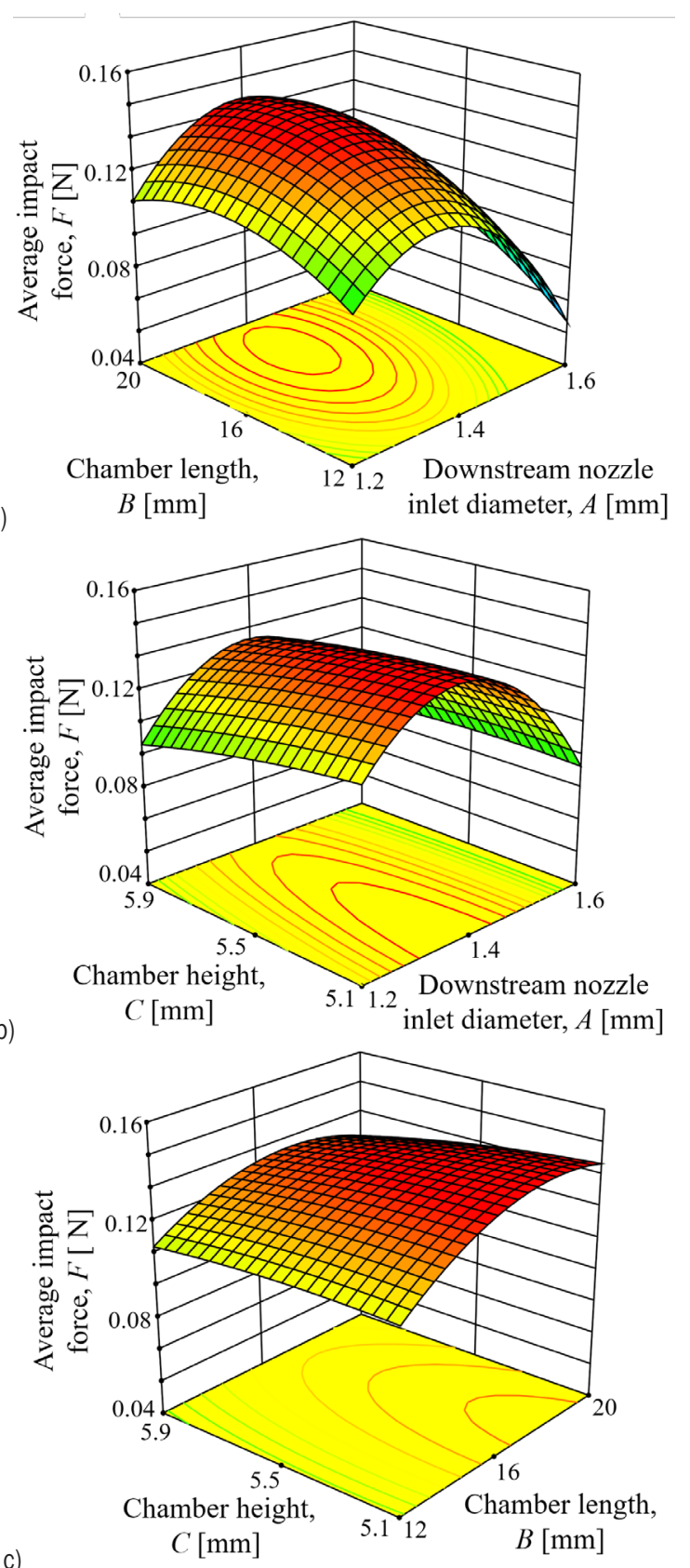

Fig. 6. Average impact force $F$ as a function of interaction items; a) Interaction item of $A$ and $B$; $b$ ) Interaction item of $A$ and $C$; c) Interaction item of $B$ and $C$

$$
\begin{aligned}
& \Delta F=+0.016-0.0008625 A+0.002188 B \\
& -0.00055 C-0.000375 A B+0.0002 A C \\
& +0.00005 B C-0.002663 A^{2}-0.002463 B^{2} \\
& -0.0006875 C^{2},
\end{aligned}
$$

It can be seen from Table 6 that the regression model $P<0.0001$ shows that the model has a very significant impact on the impact force amplitude, and can well describe the relationship between the structural parameters and the impact amplitude .

Table 6. Summary of RSM model and ANOVA for impact force amplitude

\begin{tabular}{lcccc}
\hline Source & $\begin{array}{c}\text { Sum of } \\
\text { squares }\end{array}$ & $\begin{array}{c}\text { Degrees of } \\
\text { freedom }\end{array}$ & Mean square & $\begin{array}{c}\text { Significance } \\
\text { level }\end{array}$ \\
\hline Model & $1.098 \mathrm{E}-004$ & 9 & $1.220 \mathrm{E}-005$ & $<0.0001$ \\
\hline$A$ & $5.951 \mathrm{E}-006$ & 1 & $5.951 \mathrm{E}-006$ & $<0.0001$ \\
\hline$B$ & $3.828 \mathrm{E}-005$ & 1 & $3.828 \mathrm{E}-005$ & $<0.0001$ \\
\hline$B$ & $2.420 \mathrm{E}-006$ & 1 & $2.420 \mathrm{E}-006$ & 0.0005 \\
\hline$A B$ & $5.625 \mathrm{E}-007$ & 1 & $5.625 \mathrm{E}-007$ & 0.0204 \\
\hline$A C$ & $1.600 \mathrm{E}-007$ & 1 & $1.600 \mathrm{E}-007$ & 0.1557 \\
\hline$B C$ & $1.000 \mathrm{E}-008$ & 1 & $1.000 \mathrm{E}-008$ & 0.7027 \\
\hline Residual & $4.425 \mathrm{E}-007$ & 7 & $6.321 \mathrm{E}-008$ & \\
\hline Lack of fit & $4.425 \mathrm{E}-007$ & 3 & $1.475 \mathrm{E}-007$ & \\
\hline Pure error & 0.000 & 4 & 0.000 & \\
\hline Cor Total & $1.103 \mathrm{E}-004$ & 16 & & \\
\hline
\end{tabular}

Table 6 shows the summary of RSM model and ANOVA for impact force amplitude. For the established impact force amplitude RSM model, the significant level of inlet diameter of downstream nozzle $(A)$, chamber length $(B)$ and chamber height $(C)$ are less than 0.01 which means that these three single factors have a very significant effect on impact force amplitude $\Delta F$. Similarly, the significant level of the interaction terms $(A B)$ is less than 0.05 , which indicates that only it has a significant effect on the impact force amplitude $\Delta F$.

The significance level of a certain item is inversely proportional to the influence level of the item on the average impact force. Therefore, the order of the influence of single factors the impact force amplitude $\Delta F$ is: inlet diameter of downstream nozzle $(A)=$ chamber length $(B)>$ chamber height $(C)$. The order of the influence of interaction items on the average impact force $\mathrm{F}$ is: inlet diameter of downstream nozzle and chamber length $(A B)>$ inlet diameter of downstream nozzle and chamber height $(A C)>$ chamber length and chamber height $(B C)$.

Fig. 7 shows the impact force amplitude as a function of interaction items consisting of the downstream nozzle inlet diameter, chamber length and chamber height. The interaction term $(A B)$ consisting of the length of downstream nozzle and combustor has a very significant effect on the average impact force, while the other interaction terms are less significant. Therefore, the parameters of downstream nozzle inlet diameter and chamber length are more critical for obtaining larger average impact force. 

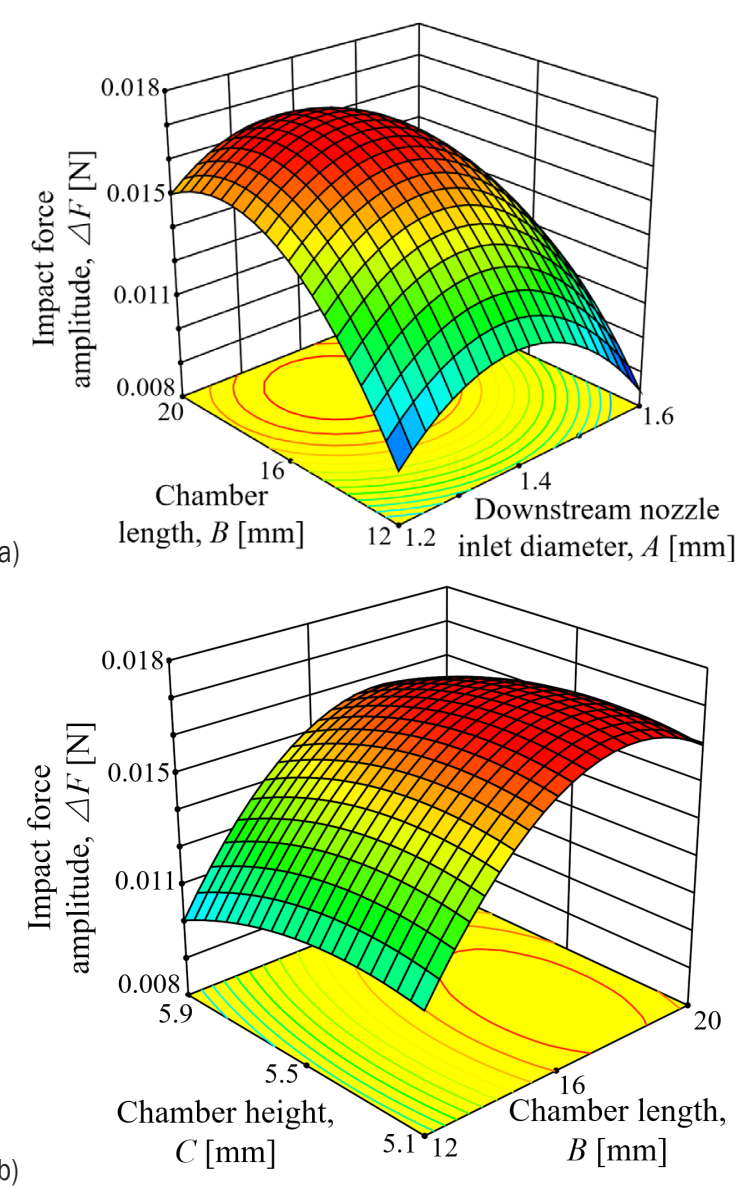

b)

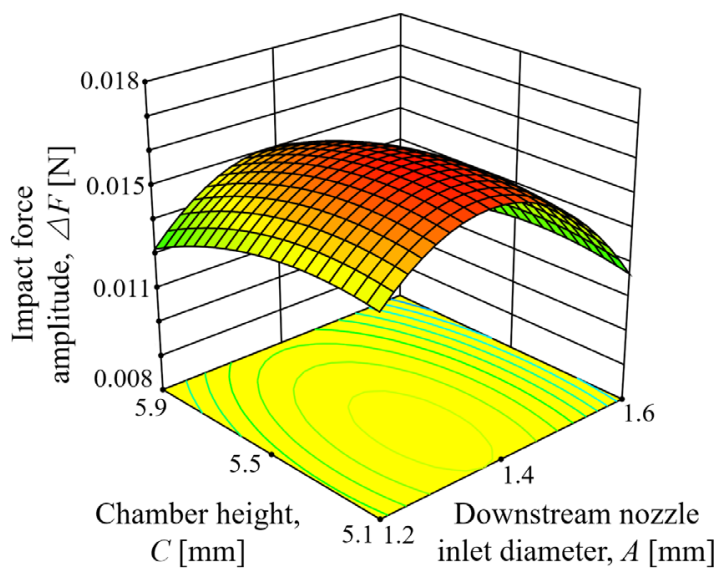

Fig. 7. Impact force amplitude $\Delta F$ as a function of interaction items; a) Interaction item of $A$ and $B$; b) Interaction item of $B$ and $C$; c) Interaction item of $A$ and $C$

According to the response surface regression equation, when the downstream nozzle inlet diameter is $1.36 \mathrm{~mm}$, the chamber length is $17.82 \mathrm{~mm}$, and the chamber height is $5.33 \mathrm{~mm}$, the impact force amplitude is expected to reach the maximum value of $0.0167 \mathrm{~N}$.

\subsection{Optimized Design Parameters}

To optimize both the average impact force value and the impact force amplitude value, the average value of chamber lengths when the average impact force value and the impact force amplitude value reach their maximum is taken as the optimized dimension of chamber length. The chamber height and the diameter of downstream nozzle are obtained by the same method, as shown in Table 7.

Table 7. Optimized dimensions

\begin{tabular}{lccc}
\hline Parameters & $\begin{array}{c}\text { Maximum average } \\
\text { impact force }\end{array}$ & $\begin{array}{c}\text { Maximum impact } \\
\text { force amplitude }\end{array}$ & Average \\
\hline $\begin{array}{l}\text { Outlet diameter } \\
\text { of upstream } \\
\text { nozzle [mm] }\end{array}$ & 1.37 & 1.36 & 1.365 \\
\hline $\begin{array}{l}\text { Chamber } \\
\text { length [mm] }\end{array}$ & 18.12 & 17.82 & 17.97 \\
\hline $\begin{array}{l}\text { Chamber } \\
\text { height [mm] }\end{array}$ & 4.80 & 5.33 & 5.065 \\
\hline
\end{tabular}

\subsection{Flow Visualization}

The pulsed water mass formed by SEPAWJ can cause strong strike force pulse, which greatly improves the cleaning performance. Fig. 8 shows the external flow field diagram of SEPAWJ before and after optimization.
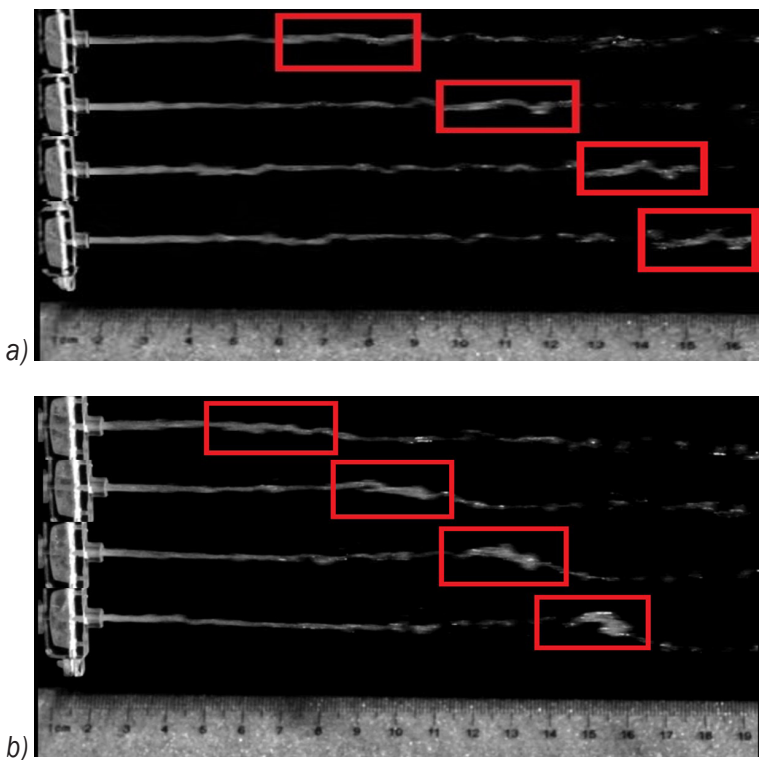

Fig. 8. External flow field diagram of SEPAWJ before and after optimization; a) flow visualization of original SEPAWJ nozzle;

b) flow visualization of optimized SEPAWJ nozzle 
Because air bubbles mixed in the jet collapse and water has surface tension in the air environment, the continuous air-water jet gradually forms small discrete water masses with different speeds. The faster small water masses will catch up with the slower small water masses and form to one large water mass. As can be seen from the external flow field diagram of original SEPAWJ in Fig. 8a, the final large water mass is formed near $16 \mathrm{~cm}$ from the nozzle exit, and it is not really concentrated and does not form a spherical shape. As shown in Fig. 8a, in the external flow field diagram of optimized SEPAWJ nozzle, the large water mass is formed close to the nozzle outlet at around 12 $\mathrm{cm}$ from the nozzle exit.

As it continues downstream, the water mass becomes concentrated and ultimately forms near spherical water mass in location around $14.5 \mathrm{~cm}$ from the nozzle exit with possessing improved cleaning capabilities.

\subsection{Analysis of Impact Force}

Fig. 9 shows the time and frequency domain diagram of SEPAWJ impact force before and after
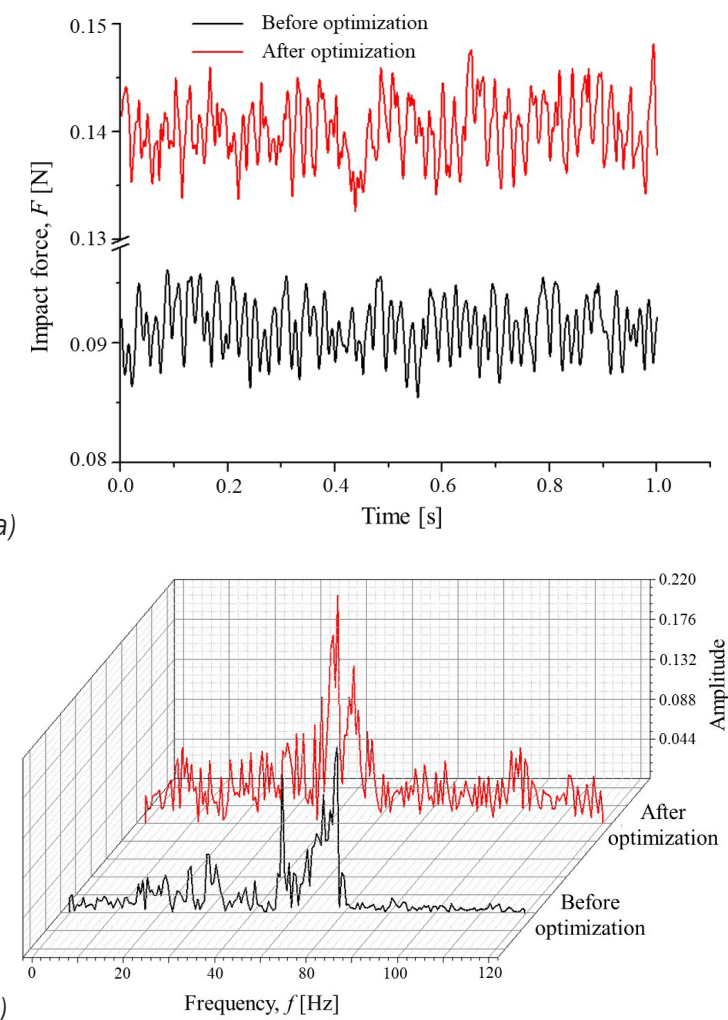

Fig. 9. Time and frequency domain diagram of SEPAWJ impact force before and after optimization; a) time domain diagram; b) frequency domain diagram optimization; it can be seen that the value of average impact force and impact force amplitude are obviously improved for the optimized nozzle, which indicates that the cleaning performance of the optimized nozzle should be greater.

Furthermore, for the optimized nozzle, the impact force intensity of fluctuations exhibits a peak in a lower frequency region around $40 \mathrm{~Hz}$. At the same mass flow rate and duration, bigger water masses definitely means less number of water masses which improves impact force amplitude and lower impact force frequency.

Table 8 shows the comparison of average impact force and impact force amplitude before and after optimization. For the SEPAWJ optimized nozzle, the average impact force is $0.1403 \mathrm{~N}$ and the impact force amplitude is 0.0159 , which are $52.00 \%$ and $38.26 \%$ higher than that of the original nozzle, respectively. This means that the impact performance of the SEPAWJ nozzle has been remarkably improved.

Table 8. Comparison of average impact force and impact force amplitude before and after optimization

\begin{tabular}{lcc}
\hline Value & $\begin{array}{c}\text { Average impact } \\
\text { force } F\end{array}$ & $\begin{array}{c}\text { Impact force } \\
\text { amplitude } \Delta F\end{array}$ \\
\hline Original [N] & 0.0923 & 0.0115 \\
\hline Optimized [N] & 0.1403 & 0.0159 \\
\hline Increase [\%] & 52.00 & 38.26 \\
\hline
\end{tabular}

Table 9. Comparison of impact force between the experiment and RSM

\begin{tabular}{lcc}
\hline Result & $\begin{array}{c}\text { Average impact } \\
\text { force } F\end{array}$ & $\begin{array}{c}\text { Impact force } \\
\text { amplitude } \Delta F\end{array}$ \\
\hline RSM model value [N] & 0.1426 & 0.0167 \\
\hline Experimental value [N] & 0.1403 & 0.0159 \\
\hline Error [\%] & 1.64 & 4.79 \\
\hline
\end{tabular}

Comparison between experimental and predicted values of the average impact force value and the impact force amplitude value are shown in Table 9. The impact force and impact force amplitude errors of prediction and experiment are both less than $5 \%$, which means that the response surface functions are basically accurate.

\subsection{Analysis of Impact Force}

The cleaning performance of SEPAWJ before and after optimization of SEPAWJ nozzle were tested. Fig. 10 is a comparison of cleaning process before and after optimization. 


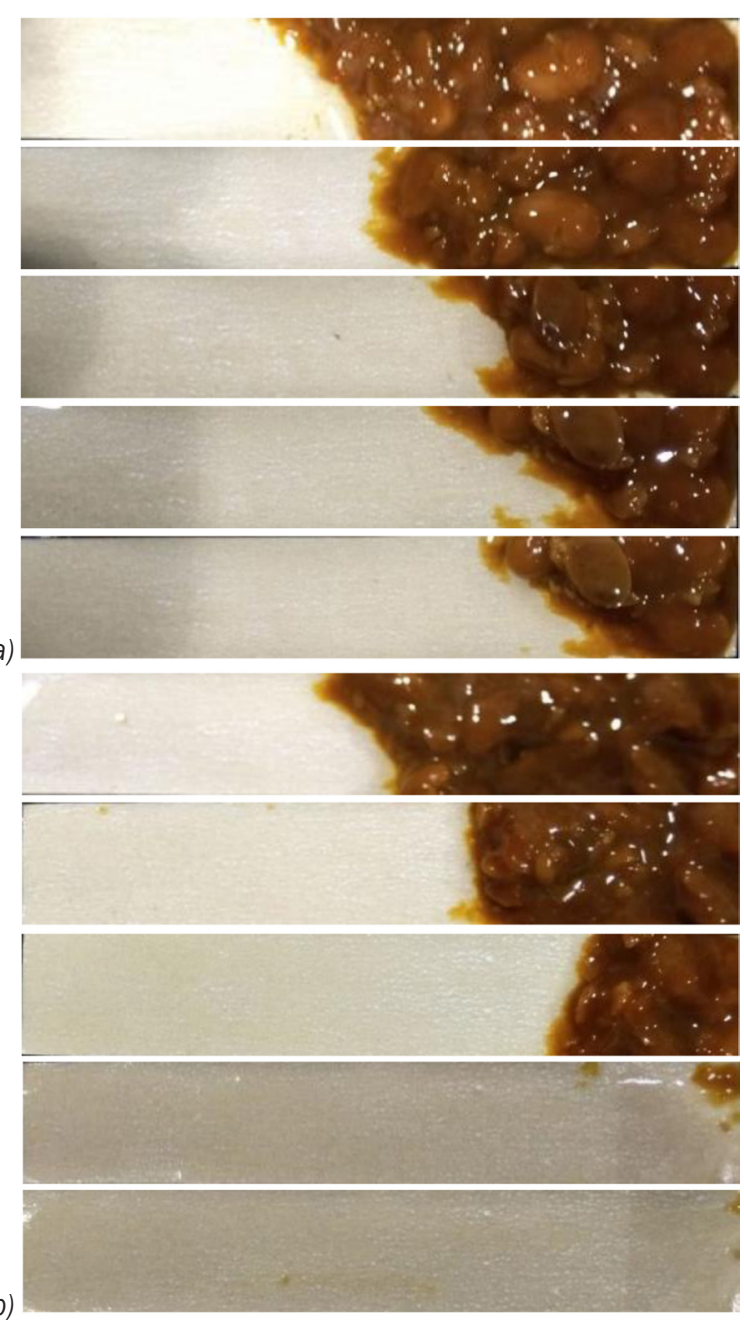

Fig. 10. Comparison of cleaning process before and after optimization; a) original nozzle; b) optimized nozzle

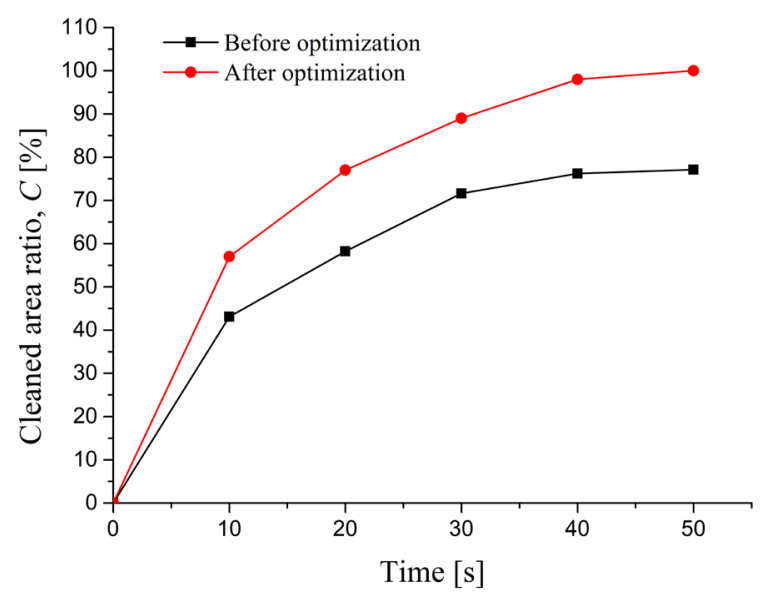

Fig. 11. Comparison of the cleaned area ratio of SEPAWJ before and after optimization
Fig. 11 shows a comparison of the cleaned area ratio of SEPAWJ before and after optimization. From the figure, it can be seen that the cleaning performance of optimized SEPAWJ on soybean paste is better than that of original SEPAWJ. At 40 seconds, the cleaned area ratio of optimized SEPAWJ reaches $96 \%$, and finally $100 \%$ at 50 seconds. However, the cleaned area ratio of original SEPAWJ reaches only $76 \%$ at 50 seconds, and the difference between them is $22.4 \%$.

In the first 20 seconds, the cleaned area ratio of the optimized and original SEPAWJ increases rapidly, and that of the original SEPAWJ increases much faster. After 20 seconds, the difference of the growth rate of the cleaned area ratio between the two SEPAWJ decreases gradually and is zero at 50 seconds. During the entire cleaning process, the cleaned area ratio of the optimized SEPAWJ is always higher than that of the original SEPAWJ. At 50 seconds, the cleaned area ratios of the two SEPAWJ do not change much more, and the difference of the cleaned area ratios between the two SEPAWJ reached the maximum of $22.4 \%$.

\section{CONCLUSION}

The second-order mathematical RSM were established for the jet characteristics of average impact force $F$ and impact force amplitude $\Delta F$ for different chamber and downstream nozzle parameters. The significance of the coefficients of the model and regression equation were tested. Single and coupling factor effects of three parameters (oscillation chamber length, oscillation chamber height and diameter of the downstream nozzle) on performance of nozzle were analysed and parameters of optimum performance were calculated using RSM. The performance of the nozzle before and after optimization was compared experimentally. The result are follows:

1. The RSM model significance levels of average impact force and impact force amplitude are both lower than 0.05 , which means that they have high significance. The most significant single factor affecting the average impact force and impact force amplitude of the SEPAWJ is the chamber length. The interactive item of the downstream nozzle inlet diameter and the chamber length has the most significant coupling effect on the SEPAWJ average impact force and impact force amplitude.

2. To maximize both modelled variables, the maximum value of parameters (average impact force and the impact force amplitude) are taken as the optimal nozzle parameters, as follows: the diameter of the upper nozzle inlet is 1.365 , the 
chamber length is $17.97 \mathrm{~mm}$, and the chamber height is $5.065 \mathrm{~mm}$.

3. The predicted values of RSM under optimized parameters are as follows: impact force is $0.1426 \mathrm{~N}$ and impact force amplitude is $0.0167 \mathrm{~N}$. The experimental values under optimized parameters are as follows: the impact force is $0.1484 \mathrm{~N}$ and the impact force amplitude is $0.0187 \mathrm{~N}$. The impact force and impact force amplitude errors of prediction and experiment are both less than $5 \%$, which means the response surface functions are basically accurate.

4. Flow visualization by high speed image acquisition shows the final large water mass of optimized SEPAWJ was formed much earlier, providing for more intensive and intermittent cleaning in comparison with original SEPAWJ.

5. Compared with original SEPAWJ, the average impact force and impact force amplitude of optimized SEPAWJ are increased by $52.00 \%$ and $38.26 \%$, respectively, and the impact force intensity of fluctuations exhibits peak in the low frequency region around $40 \mathrm{~Hz}$.

6. In the cleaning experiment at 40 seconds, the cleaned area ratio of optimized SEPAWJ reaches $96 \%$, and finally $100 \%$ at 50 seconds. However, the cleaned area ratio of original SEPAWJ reaches only $76 \%$ at 50 seconds, and the difference between them is $22.4 \%$, further showing that the optimized SEPAWJ cleaning performance is much higher in comparison with original design.

7. Although the multi-parameter optimization of self-excited pulsed air-water jet nozzle was carried out, only a few key parameters of the nozzle were selected as the optimization variables. In the future, the multi-parameter combination optimization of the self-excited pulsed air-water jet nozzle can be studied by taking into account the tilt angle of the two ends of the mixing chamber, the location and layout of the pores and the aperture of the nozzle as the optimization variables.

\section{ACKNOWLEDGEMENTS}

The authors would like to thank the support by the National Natural Science Foundation of China (51779106 and 51979126), a project funded by the Priority Academic Programme Development of Jiangsu Higher Education Institutions, Ministry of Education Xihua University (szjj2016-068). The authors would like to thank Slovenian Research
Agency (ARRS) for providing support under research programme Energy engineering P2-0401.

\section{NOMENCLATURES}

$d_{1} \quad$ Outlet diameter of upstream nozzle, [mm]

$d_{2}$ Inlet diameter of downstream nozzle, [mm]

$d_{3}$ Outlet diameter of downstream nozzle, [mm]

$H_{\mathrm{c}}$ Oscillation chamber height, [mm]

$L_{\mathrm{c}}$ Oscillation chamber length, $[\mathrm{mm}]$

$\alpha$ Inclination angle of oscillation chamber side wall, $\left[{ }^{\circ}\right]$

$\beta$ Inclination angle of oscillation chamber bottom wall, $\left[^{\circ}\right]$

$F \quad$ Average impact force, $[\mathrm{N}]$

$\Delta F$ Impact force amplitude, $[\mathrm{N}]$

\section{REFERENCES}

[1] Guha, A., Barron, R.M., Balachandar, R. (2011). An experimental and numerical study of water jet cleaning process. Journal of Materials Processing Technology, vol. 211, no. 4, p. 610-618, D0l:10.1016/j.jmatprotec.2010.11.017.

[2] Li, D., Kang, Y., Wang, X., Ding, X., Fang, Z. (2016). Effects of nozzle inner surface roughness on the cavitation erosion characteristics of high speed submerged jets. Experimental Thermal and Fluid Science, vol. 74, p. 444-452, Dol:10.1016/j. expthermflusci.2016.01.009.

[3] Chahine, G.L., Kapahi, A., Choi, J.-K., Hsiao, C.-T. (2016). Modeling of surface cleaning by cavitation bubble dynamics and collapse. Ultrasonics Sonochemistry, vol. 29, p. 528-549, DOl:10.1016/j.ultsonch.2015.04.026.

[4] Labus, T.J.,Savanick, G.A. (2001). An Overview of Waterjet Fundamental and Application. Waterjet Technology Association, Saint Louis.

[5] Glenn, L.A. (1975). The mechanics of the impulsive water cannon. Computers and Fluids, vol. 3, no. 2-3, p. 197-215, DOI:10.1016/0045-7930(75)90018-3.

[6] Grinspan, A.S., Gnanamoorthy, R. (2010). Impact force of low velocity liquid droplets measured using piezoelectric PVDF film. Colloids and Surfaces A: Physicochemical and Engineering Aspects, vol. 356, no. 1-3, p. 162-168, D0l:10.1016/j.colsurfa.2010.01.005.

[7] Dehkhoda, S., Hood, M. (2013). An experimental study of surface and sub-surface damage in pulsed water-jet breakage of rocks. International Journal of Rock Mechanics and Mining Sciences, vol. 63, p. 138-147, D0l:10.1016/j. ijrmms.2013.08.013.

[8] Tang, C.L., Hu, D., Zhang, F.H. (2011). Study on the frequency characteristic of self-excited oscillation pulsed water jet. Advanced Materials Research, p. 317-319, 1456-1461, DOI:10.4028/www.scientific.net/AMR.317-319.1456.

[9] Hu, Y.Z. (2016). Time-Frequency Feature Analysis of the Pulsed Liquid Gas Jet of the Self-Excited Inspiration Nozzle in Deep Water Conditions. MSc. Thesis, North China University of Water Resources and Hydropower, Zhengzhou. 
[10] Li, D., Kang, Y., Ding, X., Wang, X., Fang, Z. (2017). Effects of nozzle inner surface roughness on the performance of self-resonating cavitating waterjets under different ambient pressures. Strojniški vestnik - Journal of Mechanical Engineering, vol. 63, no. 2, p. 92-102, D0l:10.5545/svjme.2016.3563.

[11] Chen, B., Gao, D.R., Liang, Y.N., Zhao, J.H., Sun, Y.N. (2018). Experimental investigation of atomization and droplet turbulence characteristics of a twin-fluid nozzle with different self-excited vibrating cavity structures. Experimental Thermal and Fluid Science, vol. 99, p. 525-536, D0l:10.1016/j. expthermflusci.2018.08.017.

[12] Hall, J., Ewing, D. (2010). Spectral linear stochastic estimation of the turbulent velocity in a square three-dimensional wall jet. Journal of Fluids Engineering, vol. 132, no. 5, p. 1-9, DOl:10.1115/1.4001490.

[13] Li, D., Kang, Y., Ding, X., Wang, X., Fang, Z. (2016). Effects of area discontinuity at nozzle inlet on the characteristics of high speed self-excited oscillation pulsed waterjets. Experimental Thermal and Fluid Science, vol. 79, p. 254-265, DOI:10.1016/j.expthermflusci.2016.07.013.

[14] Oh, T.M., Cho, G.C. (2011). Energy loss from an abrasive waterjet for rock cutting. WJTA-IMCA Conference and Expo, Houston.

[15] Thakur, R.K., Singh, K.K. (2020). Abrasive waterjet machining of fiber-reinforced composites: A state-of-the-art review. Journal of the Brazilian Society of Mechanical Sciences and Engineering, vol. 42, no. 7, p. 1-25, D0l:10.1007/s40430-02002463-7.

[16] Alsoufi, M.S., Suker, D.K., Alhazmi, M.W., Azam S. (2017). Influence of abrasive waterjet machining parameters on the surface texture quality of Carrara marble. Journal of Surface Engineered Materials and Advanced Technology, vol. 7, no. 2, p. 25-37, DOI:10.4236/jsemat.2017.72003.

[17] Wang, W., Zhou, Z. (1988). Rock breaking device with pulse gas-liquid jet. Mining Technology, vol.36, p. 23-24, DOI:10.13828/j.cnki.ckjs.1988.36.015. (in Chinese)

[18] Hu, D., Li, X.-H., Tang, C.L., Kang, Y. (2015). Analytical and experimental investigations of the pulsated air-water jet. Journal of Fluids And Structures, vol. 54, p. 88-102, D0l:10.1016/j.jfluidstructs.2014.10.010.

[19] Box, G.E.P., Wilson, K. (1992). On the experimental attainment of optimum conditions. Journal of the Royal Statistical Society, vol. 8, no. 1, p. 1-38, DOl:10.1007/978-1-4612-4380-9_23.

[20] Vyavahare, G.D., Gurav, R.G., Jadhav, P.P., Patil, R.R, Aware, C.B., Jadhav, J.P. (2018). Response surface methodology optimization for sorption of malachite green dye on sugarcane bagasse biochar and evaluating the residual dye for phyto and cytogenotoxicity. Chemosphere, vol. 194, p. 306-315, DOI:10.1016/j.chemosphere.2017.11.180.
[21] Tang, P., Li, H., Chen, C., Sun, C. Z. (2016). Optimization and experiment of adjustable structural parameters for vertical impact sprinkler with working pressure. Transactions of the Chinese Society of Agricultural Engineering, vol. 32, no. 20, p. 99-107, Dol:10.11975/j.íssn.1002-6819.2016.20.013. (in Chinese)

[22] Siddhant, B.P., Jignasa, V.G. (2018). Enhanced solar cell performance by optimization of spray coated CZTs thin film using taguchi and response surface method. Journal of Materials Science Materials in Electronics, vol. 29, p. 56135623, D0l:10.1007/s10854-018-8530-5.

[23] Qi, C.X., Liu, H.J., Deng, S.X., Yang, A.H., Li, Z.D. (2018). A modeling study by response surface methodology (RSM) on Th(IV) adsorption optimization using a sulfated $\beta$-cyclodextrin inclusion complex. Research on Chemical Intermediates, vol. 44, p. 2889-911, D0l:10.1007/s11164-018-3286-3.

[24] Khoshnamvand, N., Kord, F.M., Mohammadi, A., Faraji, M. (2018). Response surface methodology (RSM) modeling to improve removal of ciprofloxacin from aqueous solutions in photocatalytic process using copper oxide nanoparticles (CuO/UV). AMB Express, vol. 8, p. 48, D0I:10.1186/s13568018-0579-2.

[25] Öztürk, S., Kahraman. M.F. (2019). Modeling and optimization of machining parameters during grinding of flat glass using response surface methodology and probabilistic uncertainty analysis based on Monte Carlo simulation. Measurement, vol. 145, p. 274-291, D0I:10.1016/j.measurement.2019.05.098.

[26] Gnanavelbabu, A., Saravanan, P. (2020). Experimental investigations of abrasive waterjet machining parameters on titanium alloy Ti-6Al-4V using RSM and evolutionary computational techniques. Advances in Unconventional Machining and Composites, p. 413-425, D0l:10.1007/978981-32-9471-4_33.

[27] Dani, D.N., Shah H.N. (2016). An experimental investigation of abrasive water jet machining on granite. International Journal for Innovative Research in Science \& Technology, vol. 3, no. 5, p. 26-31.

[28] Karakurt, I., Aydin G., Aydiner K. (2012). A study on the prediction of kerf angle in abrasive waterjet machining of rocks. Proceedings of the Institution of Mechanical Engineers, Part B: Journal of Engineering Manufacture, vol. 226, no. 9, p. 1489-1499, D0I:10.1177/0954405412454395.

[29] Gupta, V., Garg, M. P., Batra, N.K., Khanna R. (2013). Analysis of kerf taper angle in abrasive water jet cutting of Makrana white marble. Asian Journal of Engineering and Applied Technology, vol. 2, no. 2, p. 35-39.

[30] Javidan, M., Moghadam, A.J. (2021). Experimental investigation on thermal management of a photovoltaic module using water-jet impingement cooling. Energy Conversion and Management, vol. 228, no. 15, art. ID 113686, DOI:10.1016/J.enconman.2020.113686. 